\title{
SOLUTIONS FOR A SECOND-ORDER DELAY DIFFERENTIAL INCLUSION ON THE HALF-LINE WITH BOUNDARY VALUES
}

\author{
JOHN S. SPRAKER
}

Abstract. In [15], Wei solved a delay differential equation on the half-line. The current paper is an extension of these results to the set-valued case. The results involve measurable selections and the contraction mapping theorem for set-valued functions.

Mathematics subject classification (2010): Primary 26E25, 28B20, 34B40, 34A60, Secondary 34A34, 34A36, 34B15, 47H04, 47H09, 47H10, 54C60, 54C65, 58C06.

Keywords and phrases: Second order differential inclusion, fixed point, boundary value problem, contraction mapping theorem, Hausdorff metric.

\section{REFERENCES}

[1] J. P. Aubin and A. Cellina, Differential Inclusions, Springer 1984.

[2] J. P. Aubin And H. Frankowska, Set-valued Analysis, Birkhäuser, 1990.

[3] H. COVITZ AND S. B. NADLER JR., Multivalued contraction mapping in generalized metric spaces, Israel J. Math. 8, (1970), 5-11.

[4] D. C. BILES AND J. SPRAKER, Existence of positive solutions for a fourth order differential inclusion, Differential Equations and Applications 4, (2012), 539-546.

[5] J. J. BucKLEY, Graphs of measurable functions, Proc. Amer. Math. Soc. 44, no. 1, (1974), 78-80.

[6] A. CERNEA, A Filippov type existence theorem for a class of second-order differential inclusions, J. Inequalities Pure Applied Math. 9, no. 2, (2008), 1-6.

[7] A. Cernea, On a boundary value problem for a Sturm-Liouville differential inclusion, J. Sys. Sci. Complexity 23, no. 2, (2010), 390-394.

[8] S. Djebali, L. Gorniewicz, And A. Ouahab, Solution Sets for Differential Equations and Inclusions, DeGruyter, 2013.

[9] C. J. Himmelberg, Measurable relations, Fundamenta Mathematicae 87, issue 1, (1975), 53-72.

[10] Y. LiU, J. WU, AND Z. LI, Impulsive boundary value problems for Sturm-Liouville type differential inclusions, J. Sys. Sci. Complexity 20, no. 3, (2007), 370-380.

[11] H. L. Royden, Real Analysis (4th Edition), Prentice Hall, (2010).

[12] H. H. Schaefer, Topological Vector Spaces (2nd Edition), Springer, (1999).

[13] J. S. SpRAKer, Positive solutions for a fourth order differential inclusion with boundary values, Differential Equations and Applications 8, no. 1, (2016), 21-31.

[14] Y. Sun, B. L. XU, AND L. S. LiU, Positive solutions of singular boundary value problems for SturmLiouville equations, J. Sys. Sci. Math. Sci. 25, no. 1, (2005), 69-77.

[15] Y. WEI, Existence and uniqueness of solutions for a second-order delay differential equation boundary value problem on the half-line, Hindawi, Bound Value Probl (2008) 2008: 752827, https://doi.org/10.1155/2008/752827.

[16] R. Wheeden And A. Zygmund, Measure and Integral, CRC Press, (1977).

[17] Q. Zhang, AND G. Li, Semilinear second order differential inclusions with nonlinear boundary values, Inter. J. of Nonlinear Sci. 9, no. 1, (2010), 84-103. 